\title{
THE BISPHOSPHONATE ZOLEDRONATE PREVENTS VERTEBRAL BONE LOSS IN MATURE ESTROGEN-DEFICIENT RATS AS ASSESSED BY MICRO-COMPUTED TOMOGRAPHY
}

\author{
M. Glatt* \\ Novartis Pharma AG, Arthritis and Bone Metabolism Unit, Basel, Switzerland
}

\begin{abstract}
The effect of long-term treatment with the bisphosphonate zoledronate on vertebral bone architecture was investigated in estrogen-deficient mature rats. 4-month-old rats were ovariectomized and development of cancellous osteopenia was assessed after 1 year. The change of bone architectural parameters was determined with a microtomographic instrument of high resolution.

After 1 year of estrogen-deficiency, animals lost 55\% of vertebral trabecular bone in comparison to sham operated control animals. Trabecular number (Tb.N) and trabecular thickness ( $\mathrm{Tb}$. Th) were significantly reduced in ovariectomized animals, whereas trabecular separation ( $\mathrm{Tb} . \mathrm{Sp})$, bone surface to volume fraction (BS/BV) and trabecular bone pattern factor (TBPf) were significantly increased, indicating a loss of architectural integrity throughout the vertebral body. 3 groups of animals were treated subcutaneously with zoledronate for 1 year with $0.3,1.5$ and $7.5 \mu \mathrm{g} / \mathrm{kg} /$ week to inhibit osteoclastic bone degradation. Administration started immediately after ovariectomy and treatment dose-dependently prevented the architectural bone deterioration and completely suppressed the effects of estrogen deficiency at the higher doses.

The results show that microtomographic determination of static morphometric parameters can be used to quantitate the effects of drugs on vertebral bone architecture in small laboratory animals and that zoledronate is highly effective in this rat model.
\end{abstract}

Key Words: Bisphosphonate, zoledronate, vertebrae, rat, ovariectomy, estrogen-deficiency, microcomputed tomography, bone architecture, bone, morphometry.

"Address for correspondence:

Markus Glatt

Novartis Pharma AG, Arthritis and Bone Metabolism Unit, WKL-125.9.02, CH 4002 Basel, Switzerland

Telephone number: +41-61-696 4473

FAX number: +41-61-696 7228

E-mail: markus.glatt@pharma.novartis.com

\section{Introduction}

Bisphosphonate drugs are used to inhibit bone loss in a variety of clinical conditions with excessive bone resorbing activity (Fleisch, 1991; Papapoulos, 1992; Singer and Minoofar, 1995). The heterocyclic bisphosphonate zoledronate is a newer member of the third generation bisphosphonates and is a highly potent inhibitor of osteoclastic activity with low toxicity (Green et al., 1994, 1997; Pataki et al., 1997). In this study the bone preserving effects of zoledronate were studied in estrogen-depleted, mature rats.

Ovariectomy in rats is a widely used animal model for post-menopausal osteoporosis in humans (Frost and Jee, 1992; Kalu, 1991). In this model, a rapid increase of bone turnover in the appendicular and axial skeleton follows ovariectomy resulting in a negative overall bone balance (Bagi et al., 1993; Dempster et al., 1995; Lane et al., 1998; Wronski et al., 1989a, Yoshida et al., 1991). In vertebrae, cancellous osteopenia develops and continues unabated unless therapy is initiated (Mosekilde et al., 1993; Wronski et al., 1989b). To investigate the preventive effect of zoledronate in this model, 4-month-old rats were ovariectomized (OVX) and treated once weekly s.c. for one year. Changes in bone architecture were monitored at the end of the study by microcomputed tomography.

High resolution microcomputed tomography $(\mu \mathrm{CT})$ has only recently become commercially available. This technology allows 3-dimensional measurement of architectural parameters of bone in a non-destructive way (Delling et al., 1995; Rüegsegger et al., 1996; Uchiyama et al., 1997). The data presented here show that the technique is suitable for the assessment of bone static morphometric parameters in rat vertebrae. A significant and dose-dependent inhibition of OVX-induced loss of vertebral cancellous bone was found with a once weekly subcutaneous (s.c.) zoledronate treatment.

\section{Materials and Methods}

\section{Animal experiment}

The animal experiment was conducted by AEA Technology Biomedical Research in Harwell, UK. In brief, 4month-old female Sprague-Dawley rats were ovariectomized or sham operated under complete narcosis. Treatment with zoledronate (2-(imidazol-1-yl)-1hydroxyethylidene-1,1-bisphosphonic acid, synthesized by Novartis, Basel, Switzerland) began immediately after 
a

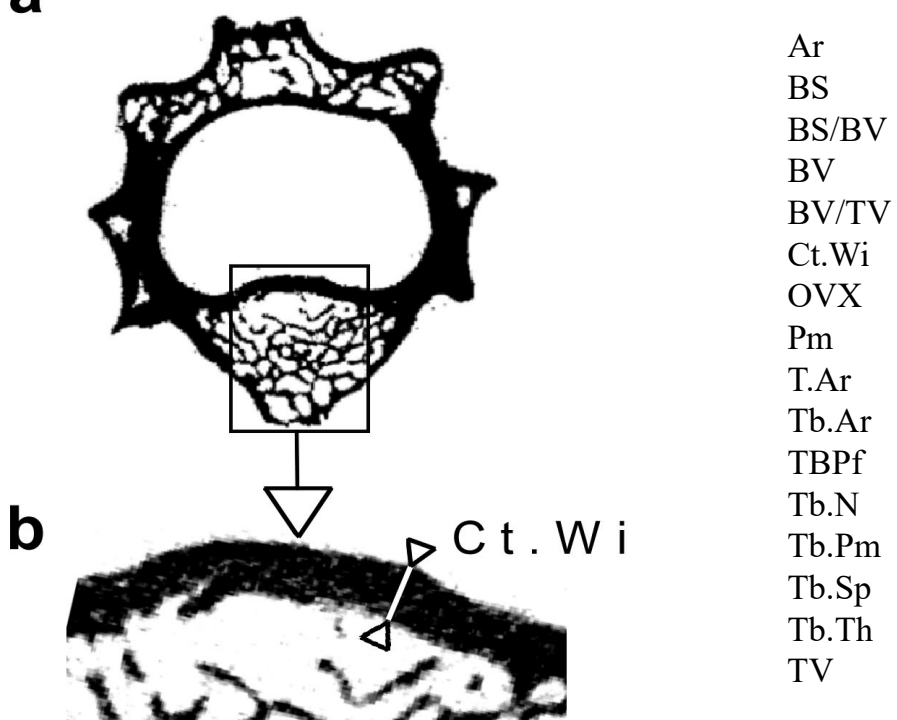

Table 1. Abbreviations

Area, $\mathrm{mm}^{2}$
Bone Surface, $\mathrm{mm}^{2}$
Bone Surface Fraction, $1 / \mathrm{mm}$
Bone Volume, $\mathrm{mm}^{3}$
Bone Volume Fraction, $\%$
Cortical Width, $\mu \mathrm{m}$
Ovariectomy
Perimeter, $\mathrm{mm}$
Tissue Area, $\mathrm{mm}^{2}$
Trabecular Area, $\mathrm{mm}^{2}$
Trabecular Bone Pattern factor, $1 / \mathrm{mm}$
Trabecular Number, $1 / \mathrm{mm}$
Trabecular Perimeter, $\mathrm{mm}$
Trabecular Separation, $\mu \mathrm{m}$
Trabecular Thickness, $\mu \mathrm{m}$
Tissue volume, $\mathrm{mm}^{3}$

Nomenclature according to Parfitt et al. (1987)

ovariectomy on the same day as the operation. Zoledronate $0.3,1.5$ or $7.5 \mu \mathrm{g} / \mathrm{kg}$ dissolved in sterile saline $(1 \mathrm{ml} / \mathrm{kg})$ was injected (s.c.) once weekly for a period of 52 weeks. Sham operated controls and ovariectomized controls were injected with saline only. Animals were housed under standard laboratory conditions (temperature $21^{\circ} \mathrm{C}$, humidity 55 $\%, 12$ hour light/dark cycles). The rats had free access to tap water and were fed with a diet containing $0.71 \%$ calcium, $0.5 \%$ phosphorous and $600 \mathrm{IU} / \mathrm{kg}$ vitamin $\mathrm{D}_{3}$. Food consumption was recorded weekly for the sham group and this amount was then fed to the OVX rats over the following week. Body weight was also recorded at weekly intervals throughout the study. At the end of the study, animals were sacrificed by carbon dioxide asphyxiation and lumbar vertebrae (LV2) were dissected free of adherent tissue, fixed in $70 \%$ ethanol and stored at $4{ }^{\circ} \mathrm{C}$.

\section{Microcomputed tomography}

Lumbar vertebrae were placed longitudinally into sample holders of a microcomputer tomograph $(\mu \mathrm{CT}-20)$ of Scanco Medical, Bassersdorf, Switzerland (Rüegsegger $e t$ al., 1996). The vertebrae were scanned perpendicularly to their longitudinal axis by a fixed X-ray fan beam $(10 \mu \mathrm{m}$ spot-size tube, $0.1 \mathrm{~mA}, 50 \mathrm{kVp}$ ) while the holder rotated along its axis. For 3-D data accumulation, the sample was moved incrementally along its axis after each turn. A total of 500 slices (1024 x 1024 pixel matrix per slice) of 13 $\mathrm{mm}$ thickness were determined, yielding a voxel size of 13 $\mathrm{x} 13 \times 13 \mu \mathrm{m}^{3}$. The resulting scan length of $6.5 \mathrm{~mm}$ was sufficiently long to cover the secondary spongiosa between both growth plates of the vertebrae. The innermost growth plate areas at both ends of vertebral bodies were used to position a core volume of interest for 3-D reconstruction (Fig. 1a,b). A core of $1.3 \times 1.3 \times 1.3 \mu \mathrm{m}^{3}$ was evaluated (100 slices of $13 \mathrm{~mm}$ thickness) with the $\mu \mathrm{CT}$ software version $2.1 \mathrm{~b}$ of Scanco Medical to determine parameters of bone morphometry. The spatial resolution with the given settings of the instrument was $24 \mu \mathrm{m}$; precision of repeated measurements was below 1\%. In 2-D mode, Tb.Ar and $\mathrm{Tb} . \mathrm{Pm}$ were derived from the binarized region of interest, 
a

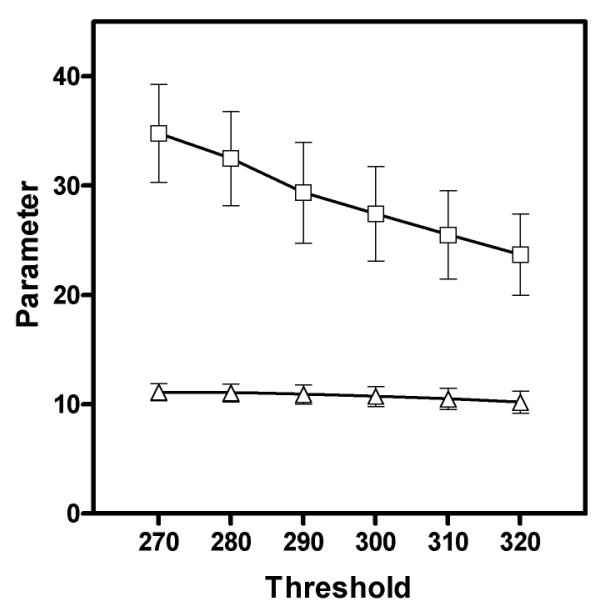

b

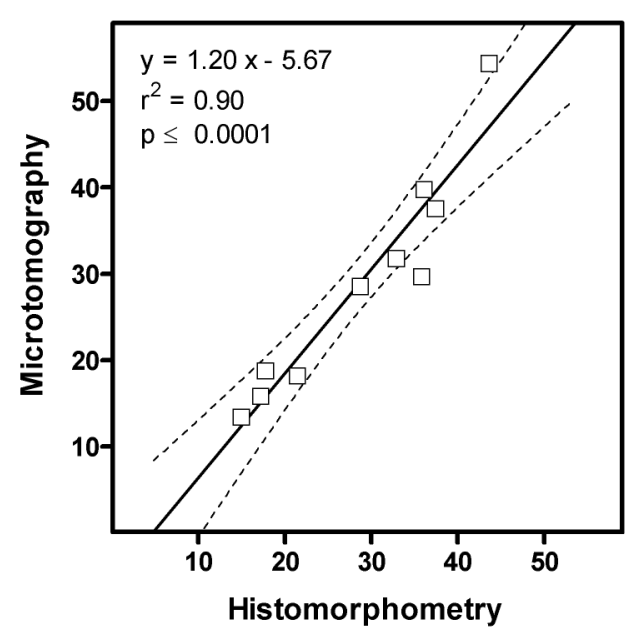

C

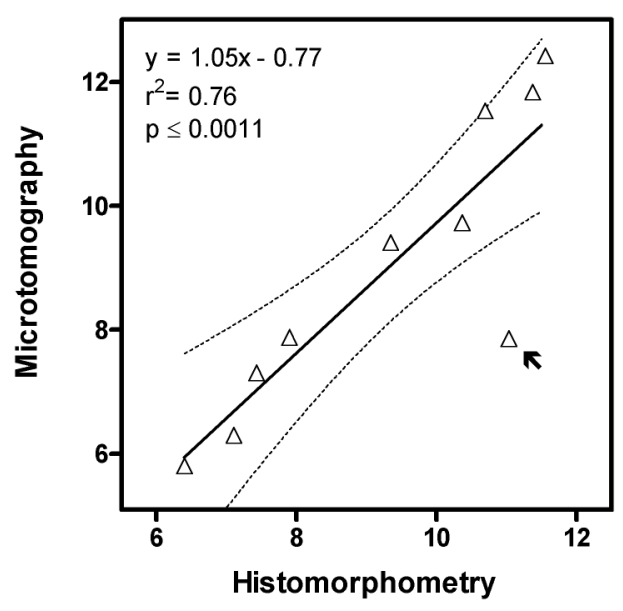

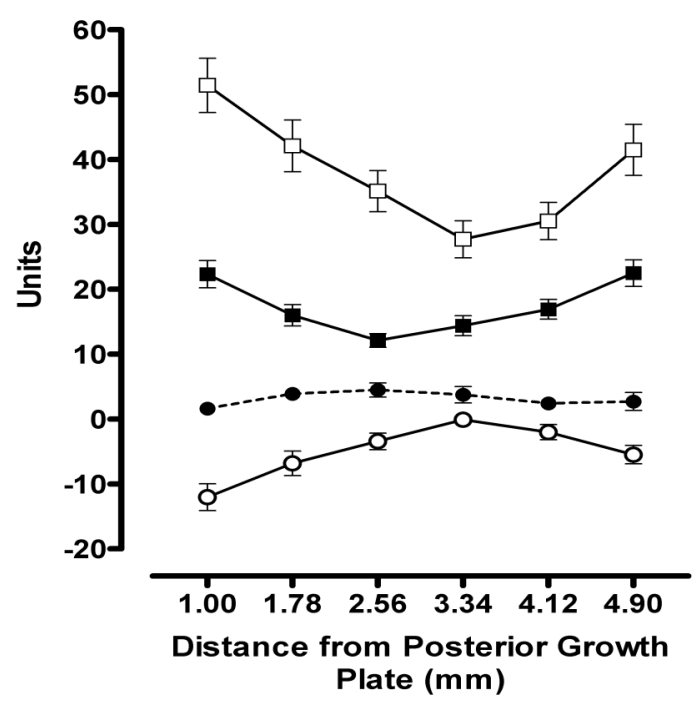

Figure 3. Longitudinal trabecular bone distribution in the vertebral body of LV2. In the midregion of vertebrae, trabecular bone has its lowest density reflected by low values for $\mathrm{Tb}$. $\mathrm{Ar}$ (open squares: $\mathrm{Tb}$. $\mathrm{Ar}$ (\%) of sham-operated control animals). OVX reduces trabecular bone density in a generalized way, the curve shifts downwards (closed squares: $\operatorname{Tb} . \operatorname{Ar}(\%)$ of OVX-rats). During this process, trabecular structures become smaller and their curvatures increase, therefore the values of TBPf shift upwards after OVX (open circles: TBPf of sham-operated animals; closed circles: TBPf of OVX-rats). Data represent means \pm standard error of the mean, $\mathrm{n}=10$.

Figure 2. Effect of threshold setting on bone parameters and their correlation with histomorphometry. (a) The values of $\mathrm{Tb}$.Ar (squares) nearly linearly decline with increasing threshold levels, whereas the threshold dependency of Tb.Pm (triangles) is less marked, (b) $\mathrm{Tb} . \mathrm{Ar}(\%)$ measurements correlate highly significantly between microtomographic and histomorphometric determinations. The microtomographic values are smaller in the lower range $(<30 \%)$ in comparison to histomorphometric values. Several factors might contribute to this effect: Very small bone structures, e.g., do not reach the critical threshold level and remain "invisible", or histological distortions during slide preparation cannot be sufficiently controlled. (c) Tb.Pm measurements correlate highly significantly between microtomography and histomorphometry. The outlier value (marked by an asterisk) has been included in the calculation. Without this outlier, $\mathrm{r}^{2}$ would reach a value of 0.97 , indicating an extremely good match. All data show means \pm standard error of the mean, $n=10$. 

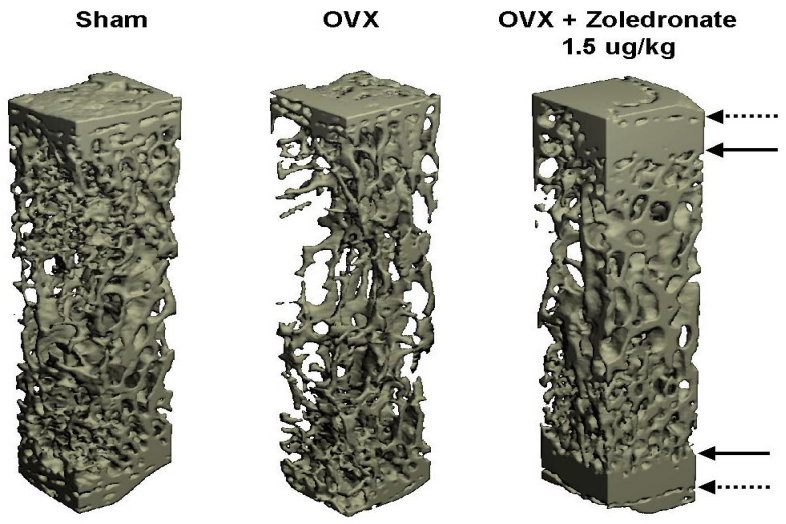

Figure 4. Full length vertebral bone cores representing approximately group average values of cancellous bone in vertebral bodies. Sham operated rats (left) show a mostly solid and interconnected trabecular framework. Trabecular thinning and fragmentation is evident in the OVX sample (center), whereas zoledronate treatment (right) preserved trabeculae and formed very dense, spongious bone between the growth plates (dotted arrows) and the bone laid down since treatment was initiated (solid arrows). Because of insufficient tomographic resolution this zone between arrows appears as a solid mass.

a

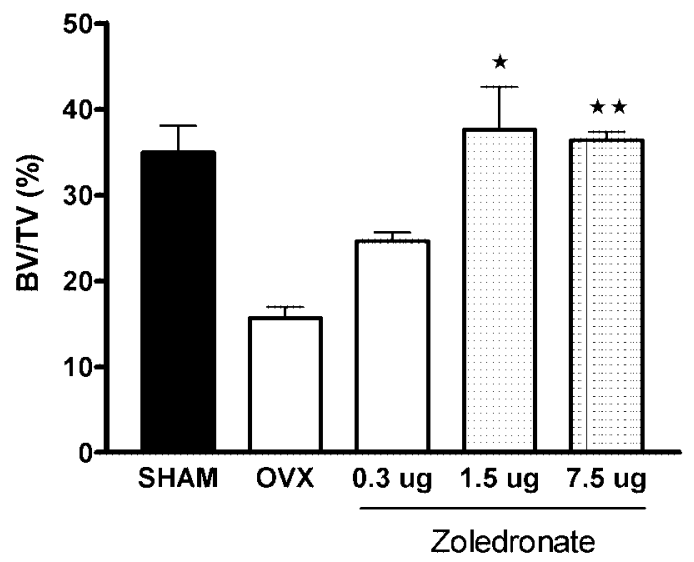

b

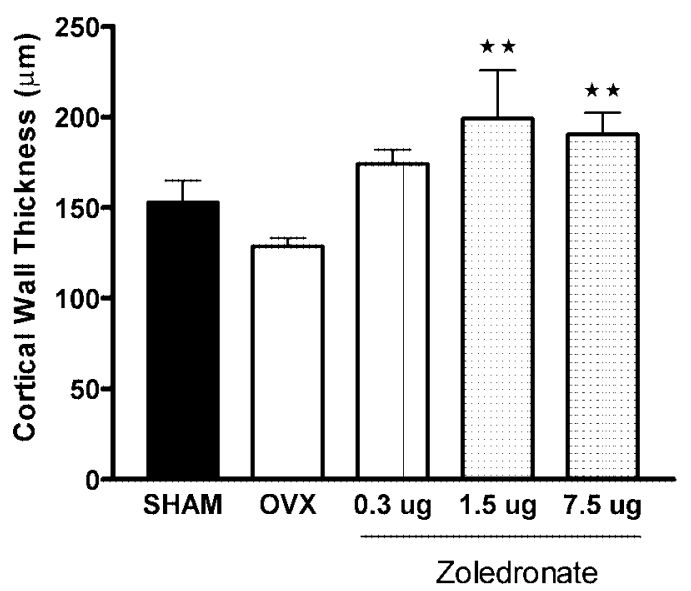

C

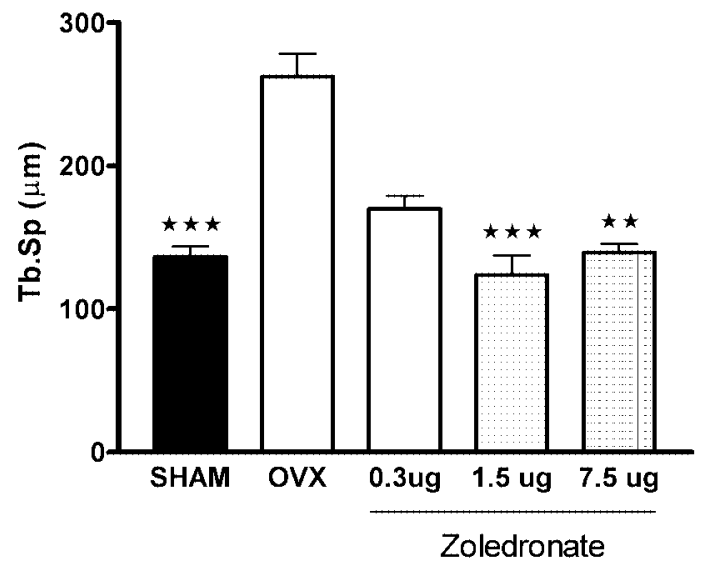

d

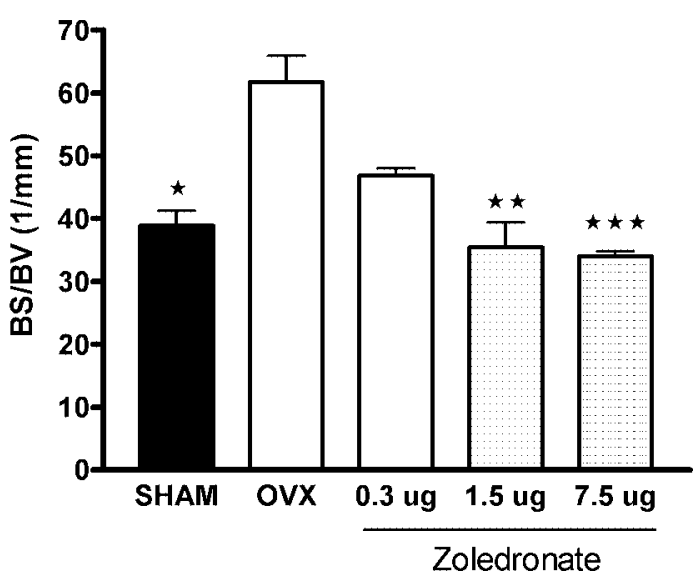

Figure 5. The effect of OVX and zoledronate treatment on morphometric bone parameters: (a) Bone volume fraction $(\mathrm{BV} / \mathrm{TV})$ is diminished following OVX. Once weekly treatment with zoledronate dose dependently prevents loss of trabecular density and maintains BV/TV above the levels of sham controls. (b) Cortical width is not significantly reduced after OVX. Zoledronate treatment dose-dependently and significantly increases vertebral cortical width. (c) Trabecular separation (Tb.Sp) significantly increases following OVX. This effect is completely prevented with higher doses of zoledronate. (d) Bone surface to volume fraction (BS/BV) is augmented after OVX. Zoledronate treatment dose-dependently and significantly prevents this effect. Bars represent means $\pm \mathrm{SEM}$, $\mathrm{n}=6-10,1$ asterisk $\mathrm{p}<0.05,2$ asterisks $\mathrm{p}<0.01,3$ asterisks $\mathrm{p}<0.001$. 
whereas the other parameters were calculated according to the plate model of Parfitt et al., $(1983,1987)$ :

Tb.N = (1.199/2.000)(Tb.Pm/T.Ar);

$\mathrm{Tb} . \mathrm{Th}=(2.000 / 1.199)(\mathrm{Tb} . \mathrm{Ar} / \mathrm{Tb} . \mathrm{Pm})$;

Tb.Sp $=(2.000 / 1.199)($ T.Ar-Tb.Ar)/Tb.Pm, and TBPf $=$ (Pm1-Pm2)/(Ar1-Ar2) according to Hahn et al. (1992).

In 3-D mode, TV, BV, Tb.N and BS were measured in the volume of interest, whereas $\mathrm{Tb} . \mathrm{Sp}$ was calculated as (1-(BV/TV))/Tb.N (Rüegsegger et al., 1996; Goulet et al., 1994). Table 1 lists the morphometric abbreviations used according to Parfitt et al. (1987).

Cortical bone width (Ct.Wi) was determined in the center of vertebrae where the inner vertebral wall separates the foramen and spinal cord on the ventral side from the vertebral body (Fig. 1b). The cortical width was measured manually with the software of Scanco Medical on the monitor at 5 positions per section.

\section{Histomorphometry}

10 undecalcified vertebrae were embedded in methylmethacrylate and scanned in the $\mu \mathrm{CT}-20$ before cutting in transversal direction with a Polycut S microtome (Leica, Wetzlar, Germany). Serial sections of $8 \mu \mathrm{m}$ thickness were made and stained by von Kossa's method and counterstained with Ponceau's acid-fuchsin solution (Romeis, 1989) before mounting. Static parameters were quantified with a Quantimed 500-system (Leica Microsystems, Glattbrugg, Switzerland) for computerized image analysis connected to a DMRBE microscope (magnification $\mathrm{x} 260$ ) with a videocamera and monitor system (Leica Microsystems). A software specially adapted for bone morphometry allows semi-automatic measurements of Tb.Ar, Tb.Pm, Tb.Th, Tb.N and Tb.Sp according to established methods (Parfitt et al., 1983; Mori et al., 1990). Mean values of 3 consecutive sections were determined and compared to 3 matched sections made with the $\mu \mathrm{CT}$ 20 apparatus.

\section{Statistics}

Statistical calculations were computed with the program Prism 2.0, GraphPad Software, San Diego, California, USA. 1-way ANOVA followed by Dunnett's post test were used to calculate levels of significance (p). If variances were not homogenous, a non-parametric test (KruskalWallis test followed by Dunn test) was performed. In group comparisons sham-operated or zoledronate-treated groups were compared with ovariectomized control animals. Cor- relations: Coefficients of determination $\left(\mathrm{r}^{2}\right)$ and levels of significance were calculated according to Pearson with the same software package. 6-10 rat vertebrae were analyzed per group (see also the section Discussion with Reviewers).

\section{Results}

A microscopic and microtomographic section through a rat vertebral body are shown in Figure 1. The resolution of the $\mu \mathrm{CT}-20$ of $24 \mu \mathrm{m}$ was sufficient to reveal the trabecular pattern of the specimens in such detail that it was possible to match corresponding histological sections with sufficient precision. However, undecalcified sections can be distorted during the sectioning and mounting processes (Lane and Ralis, 1983). Small fractures parallel to the cutting knife are frequent and can disturb morphometric measurements. In Figure 1c, e.g., micro-cracks increased the total trabecular area of the histological section by $4.8 \%$. The trabecular areas were therefore individually corrected for micro-cracks to minimize distortion of microscopic morphometric values before matching.

Matched microtomographic vertebral sections were then analyzed with varying threshold settings as shown in Figure 2a. Within the chosen range of thresholds, trabecular area declined nearly linearly with increasing threshold setting, whereas trabecular perimeter was much less affected. Therefore an optimal threshold value was calculated for 10 vertebrae to yield identical trabecular area for both histological and microtomographic measurements. These thresholds were averaged and the resulting mean threshold value was used for further determinations. With the average threshold value a highly significant positive correlation was found between histomorphometric and microtomographic determinations of bone area fraction $\left(\mathrm{p}<0.0001, \mathrm{r}^{2}=0.90\right)$ and trabecular perimeter determination $\left(p<0.0011, r^{2}=0.76\right)($ Fig. $2 b, c)$. An outlier value (marked by an arrow in Fig. 2c) has been included in the calculation. The coefficient of determination would reach 0.97 without this outlier. Other static bone morphometric parameters such as Tb.N, Tb.Th and Tb.Sp depend on area and perimeter measurements, consequently these data also correlated between microtomographic and microscopic determinations (Tb.N: $\mathrm{r}^{2}=0.76, \mathrm{p}<0.001$; Tb.Th: $\mathrm{r}^{2}=0.80$,

Table 2. Effect of zoledronate treatment on bone morphometric parameters

$\begin{array}{lllllll}\begin{array}{l}\text { TREATMENT } \\ \text { GROUP }\end{array} & \begin{array}{l}\text { TB.N } \\ 1 / \mathrm{mm}\end{array} & \mathbf{p}< & \begin{array}{l}\text { Tb.Th } \\ \mu \mathrm{m}\end{array} & \mathbf{p}< & \begin{array}{l}\text { TBPf } \\ 1 / \mathrm{mm}\end{array} & \mathbf{p}< \\ \text { SHAM } & 5.29 \pm 0.12 & 0.001 & 53.5 \pm 4.36 & 0.05 & -1.97 \pm 0.97 & 0.05 \\ \text { OVX } & 3.45 \pm 0.16 & & 33.57 \pm 2.19 & & 4.42 \pm 1.16 & \\ \text { ZOL } 0.3 \mu \mathrm{g} / \mathrm{kg} / \mathrm{w} & 4.75 \pm 0.22 & \mathrm{~ns} & 42.83 \pm 1.13 & \mathrm{~ns} & 1.38 \pm 0.32 & \mathrm{~ns} \\ \text { ZOL } 1.5 \mu \mathrm{g} / \mathrm{kg} / \mathrm{w} & 5.45 \pm 0.29 & 0.001 & 62.69 \pm 10.06 & 0.05 & -3.12 \pm 1.74 & 0.05 \\ \text { ZOL } 7.5 \mu \mathrm{g} / \mathrm{kg} / \mathrm{w} & 5.09 \pm 0.19 & 0.05 & 59.16 \pm 1.48 & 0.01 & -2.17 \pm 0.66 & 0.01\end{array}$

Data represent mean values \pm SEM, 6-10 rats per group. Statistics: One-way ANOVA with post tests (see methods), comparison against OVX, ns = not significant. 
$\mathrm{p}<0.0005 ;$ Tb.Sp: $\mathrm{r}^{2}=0.70, \mathrm{p}<0.0025$ ).

Trabecular bone is not evenly distributed throughout vertebrae. The posterior area shows generally higher trabecular density, whereas the lowest value is found in the anterior third (Fig. 3). Ovariectomy leads to an generalized and significant bone loss characterized by a diminution of plate-like structures and a transition to more slender, rod-like structures (Fig. 4). The curves of trabecular bone pattern factors (TBPf) and of BV/TV form a mirror image pattern underlining the transition to smaller structures with narrower surface curvatures in the central parts of the vertebral body (Fig. 3). Ovariectomy further accentuates this pattern and shifts TBPf towards higher values indicative of smaller structures with more rounded forms like e.g. rods or bone spicules (Table 2, Fig. 4). The vertebral bodies also showed in the ventral to dorsal direction of their central part a clear trend to less trabecular bone which was often detached from the cortical bone towards the foramen.

Mature 16 month old Sprague-Dawley rats have a naturally high percentage $(35 \%)$ of vertebral trabecular bone (Fig. 4, 5a). One year after ovariectomy, a reduction by $55 \%$ could be observed. This loss was prevented in a dosedependent way by a once weekly treatment with zoledronate for one year. A partial protection was achieved with 0.3 $\mu \mathrm{g} / \mathrm{kg}$, and with $1.5 \mu \mathrm{g} / \mathrm{kg}$ and $7.5 \mu \mathrm{g} / \mathrm{kg}$ full protection was evident that reached a plateau and no further increase could be observed at the highest dose. Trabecular number and thickness followed the same pattern (Table 2). Conversely, trabecular separation, $\mathrm{BS} / \mathrm{BV}$ and TBPf all increased following ovariectomy but remained at normal levels under zoledronate treatment (Fig. 5c, d and Table 2). In contrast to cancellous bone the vertebral cortical width was only slightly affected by ovariectomy and treatment with zoledronate prevented thinning and increased the cortical width above sham-treated controls (Fig. 5b).

\section{Discussion}

Measurement of trabecular bone loss in estrogen-deprived rats has become a widely used method to determine effectiveness of potential new anti-osteoporotic compounds (Frost and Jee, 1992; Kalu, 1991). Up to recently however, only histomorphometric methods have allowed a sufficiently detailed analysis of bone micro-architectural parameters in small rodents. With the advent of bench-top microtomographic instruments structural information can be obtained in a normal laboratory from unprocessed bone specimens with little or no preparatory work. Here we show that at the 2-D level, histomorphometric and microtomographic determinations can be matched by adjusting threshold levels of the latter such as to yield nearly identical values. This method has been used by others with good results (Uchiyama et al., 1997; Müller et al., 1998). Nevertheless, our simple method to correct bone areas does not completely take into account artefactual distortions of histological slides [e.g., by shrinkage or compression during processing (Lane and Ralis, 1983)] other than by micro-cracks and therefore may be inaccurate to some extent. The higher tissue density of rat bone in comparison to man (Aerssens et al., 1998) requires threshold adjustment for the $\mu \mathrm{CT}$ readings. Alternative methods of physical volume calibration such as micropyknometry could be used for small and complex porous bone samples from laboratory animals (Zou et al., 1997).

The correlation between 2-D microtomographic and histomorphometric determinations of the parameter B.Ar (Fig. $2 \mathrm{~b}, \mathrm{r}^{2}=0.90$ ) was very similar to the corresponding value $\left(\mathrm{r}^{2}=0.90\right)$ published by Uchiyama et al., (1997). Müller et al. (1998) used a different approach to correlate 3-D microtomographic and 2-D histomorphometric measurements. Following measurement of unprocessed bone biopsies with a $\mu \mathrm{CT}$, bone samples were processed and embedded in methacrylate for standard histomorphometry. Matched sections showed coefficients of determination of 0.86 for $\mathrm{BV} / \mathrm{TV}$, and 0.83 for $\mathrm{BS} / \mathrm{TV}$. The latter value shows a better correlation to the one reported here $\left(\mathrm{r}^{2}=0.76\right.$, Fig. $3 b)$, although the data are not strictly comparable as we compared 2-D based morphometric parameters. Without the outlier value (marked by an arrow) in the lower right corner of Fig. 2c, $r^{2}$ would increase to 0.97 . The correlations of Tb.N, a parameter based on B.Pm measurement (Parfitt et al.,1983), had as expected a similar value of $\mathrm{r}^{2}$ as the correlations of Tb.Pm. Tb.Th showed a close match $\left(\mathrm{r}^{2}=0.80\right)$, whereas Tb.Sp as assessed by histomorphometry yielded generally higher values than microtomographic determinations. Ito et al. (1998) also compared 2D microtomographic and histomorphometric measurements obtained from human iliac crest biopsies and reported coefficients of correlation $(r)$ in the range of 0.63 to 0.86 .

Vertebral bone loss after ovariectomy is characterized by a significant reduction of trabecular bone volume and number, whereas trabecular thickness tends to be less affected (Lane et al., 1998; Wronski et al., 1989b; Mosekilde et al., 1993). In this investigation, we found significant effects of estrogen depletion on all these parameters after a 1 year observation period. Zoledronate is an extremely potent inhibitor of osteoclastic bone resorption (Green $e t$ al., 1994), $0.3 \mu \mathrm{g} / \mathrm{kg} / \mathrm{week}$ partially, and 1.5 and $7.5 \mu \mathrm{g} /$ $\mathrm{kg}$ /week completely prevented bone loss following ovariectomy. Zoledronate treatment dose-dependently prevented the osteopenic effects of estrogen deficiency and had a prominent protective effect on trabecular thinning (Table 2) as can also be seen from the corresponding BS/ BV and TBPf values (Fig. 5d and Table 2). TBPf is sensitive to transitions from plates to rods and high values indicate bone areas where plate fragmentation and fenestration are taking place (Amling et al., 1996). Perforation of trabeculae and subsequent cavity enlargement by osteoclasts have been shown to be responsible for this loss of cancellous structural integrity (Abe et al., 1999). Figures 3 and 4 illustrate bone distribution in the vertebral body along its axis and show a nadir in the central part where the oldest trabecular bone fraction is located. Ovariectomy leads to a generalized loss of about $50 \%$ in all parts of the vertebral body that is effectively counteracted by zoledronate.

The mode of action of bisphosphonates is not fully understood at the molecular level (Rodan, 1998). It is clear, however, that zoledronate and other bisphosphonates block 
osteoclastic activity (Russell and Rogers, 1999) and thereby increase the primary spongiosa in growing bone. A very dense zone of mineralized cartilage septa, primary and secondary spongiosa adjacent to the growth plates can be observed if a sufficiently high dose is administered for a prolonged period of time (Pataki et al., 1997). This phenomenon was also observed in our study: In Figure 4 the zoledronate-treated bone core shows the formation of an $\mathrm{X}$-ray dense zone beneath both growth plates (marked by arrows) that is composed of very fine trabecular structures below the resolution of the $\mu \mathrm{CT}$ instrument.

The accelerated bone turnover rate in estrogen-deficient rats (Grynpas et al., 1992; Kippo et al., 1997; Lepola et al., 1996; Wronski, 1991) is suppressed by bisphosphonates and markers of osteoclastic bone resorption are markedly reduced (Kippo et al., 1997; Lepola et al., 1996). As a result, vertebrae of long-term treated animals maintain trabecular structures of higher mineralization (Grynpas et al., 1992) and higher mechanical strength against compressive forces compared to untreated sham-operated controls (Acito et al., 1994; Lepola et al., 1996). The correlation of increased cancellous bone mass with increased mechanical strength in vertebrae of bisphosphonate treated animals (Katsumata et al., 1995; Lafage et al., 1995; Motoie et al., 1995; Toolan et al., 1992) suggests that zoledronate-induced augmentation of vertebral cancellous bone mass would also positively affect the mechanical properties of vertebrae in estrogen-deficient animals. The maintenance of vertebral cortical width would substantially add to this effect as it has been shown that the bone mineral density of the cortical shell correlates with the fracture load in compression tests (Haidekker et al., 1999). Data corroborating this notion have been obtained in rats subjected to an identical treatment with zoledronate as used in this study and will be published elsewhere (Green et al., manuscript in preparation).

\section{Acknowledgements}

The author gratefully acknowledges the provision of bone samples and the critical reading of the manuscript by Dr. J. Green. He thanks Ms. V. Ritter and Ms. A. Studer for their help with histology and morphometry, and Dr. B. Koller for his valuable support of tomography.

\section{References}

Abe T, Sato K, Miyakoshi N, Kudo T, Tamura Y, Tsuchida T, Kasukawa Y (1999) Trabecular remodeling processes in the ovariectomized rat: Modified node-strut analysis. Bone 24: 591-596.

Acito AJ, Kasra M, Lee JM, Grynpas MD (1994) Effects of intermittent administration of pamidronate on the mechanical properties of canine cortical and trabecular bone. J Orthop Res 12: 742-746.

Aerssens J, Boonen S, Lowet G, Dequeker J (1998) Interspecies differences in bone composition, density, and quality: potential implications for in vivo bone research. Endocrinology 139: 663-670.
Amling M, Pösl M, Ritzel H, Hahn M, Vogel M, Wening VJ, Delling G (1996) Architecture and distribution of cancellous bone yield vertebral fracture clues. Arch Orthop Trauma Surg 115: 262-269.

Bagi CM, Mecham M, Weiss J, Miller SC (1993) Comparative morphometric changes in rat cortical bone following ovariectomy and/or immobilization. Bone 14: 877 883

Delling G, Hahn M, Bonse U, Busch F, Günnewig O, Beckmann F, Uebbing H, Graeff W (1995) New applications of structure analysis of bone biopsies in microcomputed tomography. Pathologe 16: 342-347.

Dempster DW, Birchman R, Xu R, Lindsay R, and Shen V (1995) Temporal changes in cancellous bone structure of rats immediately after ovariectomy. Bone 16: 157-161.

Fleisch H (1991) Bisphosphonates. Pharmacology and use in the treatment of tumor-induced hypercal-caemic and metastatic bone disease. Drugs 42: 919-944.

Frost HM, Jee WSS (1992) On the rat model of human osteopenias and osteoporoses. Bone Mineral 18: 227-236.

Goulet RW, Goldstein SA, Ciarelli MJ, Kuhn JL, Brown MB, Feldkamp LA (1994) The relationship between the structural and orthogonal compressive properties of rabecular bone. J Biomechanics 27: 375-389.

Green JR, Müller K, Jaeggi K (1994) Preclinical pharmacology of CGP 42'446, a new, potent, hetero-cyclic bisphosphonate compound. J Bone Mineral Res 5: 745751 .

Green JR, Seltenmeyer Y, Jaeggi K, Widler L (1997) Renal tolerability profile of novel, potent bisphosphonates in two short-term rat models. Pharmacol Toxicol 80: 225230.

Grynpas MD, Acito A, Dimitriu M, Mertz BP, Véry JM (1992) Changes in bone mineralization, architecture and mechanical properties due to long-term (1 year) administration of pamidronate (APD) to adult dogs. Osteoporosis Int 2: 74-81.

Hahn M, Vogel M, Pompesius-Kempa M, Delling G (1992) Trabecular bone pattern factor - a new parameter for simple quantification of bone micro-architecture. Bone 13: $327-330$.

Haidekker MA, Andresen R, Werner HJ (1999) Relationship between structural parameters, bone mineral density and fracture load in lumbar vertebrae, based on highresolution computed tomography, quanti-tative computed tomography and compression tests. Osteoporosis Int 9: 433440.

Ito M, Nakamura T, Matsumoto T, Tsurusaki K, Hayashi K (1998) Analysis of trabecular micro-architecture of human iliac bone using microcomputed tomography in patients with hip arthrosis with or without vertebral fracture. Bone 23: 163-169.

Kalu DN (1991) The ovariectomized rat model of postmenopausal bone loss. Bone Mineral 15: 175-192.

Katsumata T, Nakamura T, Ohnishi H, Sakurama T (1995) Intermittent cyclical etidronate treatment maintains the mass, structure and the mechanical property of bone in ovariectomized rats. J Bone Mineral Res 10: 921-931.

Kippo K, Hannuniemi R, Laurén L, Peng Z, Isaksson P, Virtamo T, Osterman T, Pasanen I, Sellman R, Väänänen $\mathrm{R}$ (1997) Clodronate prevents bone loss in aged ovariect- 
omized rats. Calcif Tissue Int 61: 151-157.

Lafage MH, Balena R, Battle MA, Shea M, Seedor GJ, Klein H, Hayes W, Rodan G (1995) Comparison of alendronate and sodium fluoride effects on cancellous and cortical bone in minipigs. A one-year study. J Clin Invest 95: $2127-2133$.

Lane J, Ralis ZA (1983) Changes in dimensions of large cancellous bone specimens during histological preparation as measured on slabs from human femoral heads. Calcif Tissue Int 35: 1-4.

Lane NE, Thompson JM, Haupt D, Kimmel D, Modin G, Kinney JH (1998) Acute changes in trabecular bone connectivity and osteoclast activity in the ovariectomized rat in vivo. J Bone Mineral Res 13: 229-236.

Lepola VT, Kippo K, Hannuniemi R, Laurén L, Virtamo T, Osterman T, Jalovaara P, Sellman R, Väänänen HK (1996) Bisphosphonates clodronate and etidronate in the prevention of ovariectomy-induced osteopenia in growing rats. J Bone Miner Res 11: 1508-1517.

Mori S, Jee WSS, Li XJ, Li XJ, Chan S, Kimmel DB (1990) Effects of prostaglandin $E_{2}$ on production of new cancellous bone in the axial skeleton of ovariectomized rats. Bone 11: 103-113.

Mosekilde L, Danielsen CC, Knudsen UB (1993) The effect of aging and ovariectomy on the vertebral bone mass and biomechanical properties of mature rats. Bone 14: 16.

Motoie H, Nakamura T, O’Uchi N, Nishikawa H, Kanoh H, Abe T, Kawashima H (1995) Effects of the bisphosphonate YM175 on bone mineral density, strength, structure, and turnover in ovariectomized beagles on concomitant dietary calcium restriction. J Bone Mineral Res 10: $910-920$.

Müller R, van Campenhout H, van Damme, van der Perre G, Dequeker J, Hildebrand T, Rüegsegger P (1998) Morphometric analysis of human bone biopsies: A quantitative structural comparison of histological sections and micro-computed tomography. Bone 23: 59-66.

Papapoulos SE, Landman JO, Bijvoet OLM, Löwik CWGM, Valkema R, Pauwels EKJ, Vermeij P (1992) The use of bisphosphonates in the treatment of osteoporosis. Bone 13: S41-S49.

Pataki A, Müller K, Green J, Ma YF, Li QN, Jee WSS (1997) Effects of short term treatment with the bisphosphonates zoledronate and pamidronate on rat bone: A comparative histomorphometric study on the cancellous bone formed before, during, and after treatment. Anatom Rec 249: 458-468.

Parfitt AM, Mathews CHE, Villanueva AR, Kleerekoper M, Frame B, Rao DS (1983) Relationship between surface, volume, and thickness of iliac trabecular bone in aging and in osteoporosis. J Clin Invest 72: 13961409.

Parfitt AM, Drezner MK, Glorieux FH, Kanis JA, Malluche H, Meunier PJ, Ott SM, Recker R (1987) Bone histomorphometry: Standardization of nomenclature, symbols and units. J Bone Mineral Res 2: 595-610.

Rodan GA (1998) Mechanisms of action of bisphosphonates. Ann Rev Pharmacol Toxicol 38: 375-388.

Romeis B (1989) Mikroskopische Technik (Microscopical Technique). Böck P, ed. Urban und
Schwarzenberg, München. pp. 559-560.

Rüegsegger P, Koller B, Müller R (1996) A microtomographic system for the nondestructive evaluation of bone architecture. Calcif Tissue Int 58: 24-29.

Russell RGG, Rogers MJ (1999) Bisphosphonates: From the laboratory to the clinic and back again. Bone 25: 97-106.

Singer FR, Minoofar PN (1995) Bisphosphonates in the treatment of disorders of mineral metabolism. Adv Endocrinol Metab 6: 259-288.

Toolan BC, Shea M, Myers ER, Borchers RE, Seedor JG, Quartuccio H, Rodan G, Hayes WC (1992) Effects of 4-amino-1-hydroxybutylidene bisphosphonate on bone biomechanics in rats. J Bone Miner Res 7: 1399-1406.

Uchiyama T, Tanizawa T, Muramatsu H, Endo N, Takahashi HE, Hara T (1997) A morphometric com-parison of trabecular structure of human ilium between microcomputed tomography and conventional histo-morphometry. Calcif Tissue Int 61: 493-498.

Wronski TJ, Dann LM, Scott KS, and Cintron M (1989a) Long-term effects of ovariectomy and aging on the rat skeleton. Calcif Tissue Int 45: 360-366.

Wronski TJ, Dann LM, Horner SL (1989b) Time course of vertebral osteopenia in ovariectomized rats. Bone 10: 295-301.

Wronski TJ, Yen C-F, Scott KS (1991) Estrogen and diphosphonate treatment provide long-term pro-tection against osteopenia in ovariectomized rats. J Bone Miner Res 6: 387-394.

Yoshida S, Yamamuro T, Okumura H, Takahashi H (1991) Microstructural changes of osteopenic trabeculae in the rat. Bone 12: 185-194.

Zou L, Bloebaum RD, Bachus KN (1997) Reproducibility of techniques using Archimedes' principle in measuring cancellous bone volume. Med Eng Phys 19: 63-68.

\section{Discussion with Reviewers}

G. Daculsi: How many rats were used in this study? Author: The 1 year study was initiated with 10 mature rats per group. For some groups less than 10 bone samples (LV2) were finally available for analysis: Sham 9, OVX 9, ZOL $(0.3 \mu \mathrm{g}) 6$, Zol $(1.5 \mu \mathrm{g}) 7$, and ZOL (10 $\mu \mathrm{g}) 10$ vertebrae. We used some vertebrae to optimize the histological method because long-term zoledronate treatment with high doses made the bones so hard that our attempts to prepare undecalcified sections failed and the knives of microtomes got damaged. Therefore we sacrificed a few vertebrae for decalcification and development of a new staining procedure that yielded equivalent results to von Kossa's method and was suitable for semi-automatic computerized image analysis. All this happened before a computer microtomograph became accessible.

Microtomography and comparative histomorphometry as shown in this paper have been made with methacrylate embedded, undecalcified vertebrae which were still available. After tomography of intact vertebrae within the blocks, they were cut and histologically processed as described in the methods section. Cracks in the sections contributed on average about $12 \%$ to $\mathrm{Tb}$.Ar, a range from $4-24 \%$ was de- 
termined in this experimental series.

G. Daculsi: Bone histomorphometry on undecalcified sections has been made in several studies using scanning electron microscopy (SEM) and back-scattered scanning electron microscopy (BSE) on polished sections. Have you some experience in this field, have you some comments? Author: I have no experience with these methods. Just on theoretical grounds I guess that the high resolution of EM possibly also limits its use for $3 \mathrm{D}$ reconstructions at the level of bone architecture (hundreds or more of $\mathrm{mm}^{3}$ ): The amount of data would increase and would probably require considerable data acquisition and computing time. On the other hand, backscattered EM yields qualitative and quantitative information on bone mineral composition that is not available with microtomography. A true advantage of the tomographic method is its simplicity, at least as far as the sample preparation is concerned: A roughly dissected bone can be stuck into the machine and measured without any additional preparation. Furthermore, the true $3 \mathrm{D}$ reconstruction of bone architecture allows model independent analysis of static parameters of the whole volume of interest (VOI), whereas standard histomorphometry relies on ideal srtucture model assumptions and on a limited number of slices that represent only a small fraction of the real VOI. 